\title{
Erratum zu: Science First, Sales Second! Transformation im Vertrieb in Pharma- Deutschland, von analog bis digital
}

\section{Errratum zu:}

Thomas Marco Steinle, Digitale Transformation von Dienstleistungen im Gesundheitswesen VII, https://doi.org/10.1007/978-3-658-26670-7

Auf Wunsch des Autors wurde der Name des Beitragsautors für Kapitel 9 von „Alexandra Trudnowski“ zu „Thomas Marco“ geändert.

Kapitel 9: Der Name der Beitragsautorin wurde ohne Genehmigung von der Qualitätsabteilung geändert. Die Autorenaffiliation muss wieder auf die ursprüngliche Version im Manuskript angepasst werden.

Die aktualisierte Version des Kapitels finden Sie unter https://doi.org/10.1007/978-3-658-26670-7_9 